\title{
Abstract \\ Experimental Tests on Bond Performance between Corroded Steel Reinforcements and Concrete ${ }^{\dagger}$
}

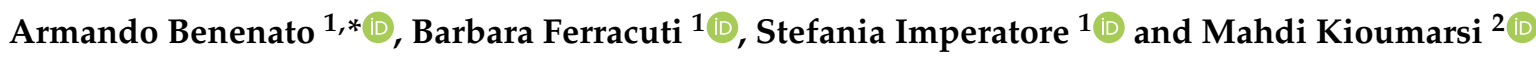 \\ 1 Department of Civil Engineering, “Niccolò Cusano" University, Via Don Carlo Gnocchi, 3, 00166 Rome, Italy \\ 2 Department of Civil Engineering and Energy Technology, Oslo Metropolitan University, Pilestredet 35, \\ 0166 Oslo, Norway; mahdik@oslomet.no \\ * Correspondence: armando.benenato@unicusano.it \\ † Presented at the First Corrosion and Materials Degradation Web Conference, 17-19 May 2021; \\ Available online: https://cmdwc2021.sciforum.net/.
}

Citation: Benenato, A.; Ferracuti, B.; Imperatore, S.; Kioumarsi, M.

Experimental Tests on Bond

Performance between Corroded Steel Reinforcements and Concrete. Mater. Proc. 2021, 6, 26. https://doi.org/ 10.3390/CMDWC2021-09972

\section{Academic Editor:}

David M. Bastidas

Published: 8 May 2021

Publisher's Note: MDPI stays neutral with regard to jurisdictional claims in published maps and institutional affiliations.

Copyright: (c) 2021 by the authors. Licensee MDPI, Basel, Switzerland. This article is an open access article distributed under the terms and conditions of the Creative Commons Attribution (CC BY) license (https:// creativecommons.org/licenses/by/ $4.0 /)$.

\begin{abstract}
The corrosion of steel bars in concrete is a dangerous and extremely costly problem that causes losses of serviceability and structural capacity in buildings and bridges. Once the depassivation occurs, because of concrete carbonation or chloride attack, the oxides occupy approximately 2-6 times the iron volume, causing a pressure at the steel-concrete interface, and consequently cracks and bond-slip degradation. In particular, the reinforcement-concrete bond degradation influences the deformability of the element and consequently its service behavior. The present study is a part of an extensive research project-CONSTIN, between Oslo Metropolitan University and Niccolò Cusano University-aiming to evaluate the steel-to-concrete interaction in the presence of corrosion and to establish a variation law for the bond strength as a function of the corrosion level. The research assess the influence of different levels of corrosion on the interaction between the concrete and the most typical steel reinforcement typologies (steel strands and smooth and ribbed bars), characterized by the same diameter (equivalent to $12 \mathrm{~mm}$ ) and bonded length. The different level of corrosion is reached with a specific duration of exposition of the embedded reinforcements to the accelerated electrolytic corrosion process. Some details about the laboratory procedure, the duration of exposition and the current density are provided. The preliminary results of the experimental campaign are presented.
\end{abstract}

Keywords: corrosion; bond-slip relationship; experimental tests

Supplementary Materials: The following supporting information can be downloaded at: https: / /www.mdpi.com/article/10.3390/CMDWC2021-09972/s1.

Funding: This research received no external funding.

Institutional Review Board Statement: Not applicable.

Informed Consent Statement: Not applicable.

Data Availability Statement: The raw/processed data required to reproduce these findings cannot be shared at this time as the data also forms part of an ongoing study.

Acknowledgments: The paper is part of the research "Effect of corrosion on the steel-to-concrete interaction (CONSTIN)" between Niccolò Cusano University and Oslo Metropolitan University, that financially support the project. 